\title{
Risk: more questions than answers
}

\author{
INVITED COMMENTARY ON... PSYCHODYNAMIC METHODS IN RISK ASSESSMENT
}

AND MANAGEMENT

Frank Holloway

\section{The risk industry in psychiatry}

The rise of the risk industry in psychiatry in England and Wales can be given a precise date: 17 December 1992. That was the day that Christopher Clunis, a man who had been in contact with psychiatric services for some 6 years, murdered Jonathan Zito in an unprovoked attack. This tragedy received enormous publicity and resulted in a flurry of activity within the Department of Health. As a result of the moral panic surrounding Clunis, which crystallised long-term trends, the assessment and management of risk became a central focus of mental health policy and practice (Holloway, 1996). Risk remains a core issue, and indeed mental health services have come to be seen as a key element in a strategy for public protection that aims to keep people who are identified as a potential risk to others off the streets. (We await, with some professional trepidation, the legislation that will provide a sufficiently broad definition of mental illness to fully legitimate this social role.) Mental health staff are now required by government policy and their employers to assess an everexpanding range of risks - most recently, following the Victoria Climbié Inquiry (House of Commons Health Committee, 2003), risks to dependent children, generally with the aid of unvalidated risk assessment tools. Increasingly, mainstream mental health services are being expected to provide interventions for people whose presenting problems are risky behaviours (or even risky feelings) rather than to offer treatment for mental illness.

Forensic psychiatrists would argue that it was ever thus: as a profession we have always had to respond to societal concerns about deviant, disordered behaviour as well as helping to differentiate those who deserve punishment from those who should be treated or humanely contained.

\section{Why risk isn't just a burden}

As one of the 12 steps to a safer service all mental health staff, we are instructed, must receive formal training in risk assessment every 3 years (Appleby et al, 2001). Busy professionals may find this prospect dreary but there are, in fact, reasons to embrace this opportunity. Looking thoughtfully at risk raises a whole series of fascinating questions within a wide range of intellectual disciplines (Box 1): rigorous thinking in these areas can only improve our practice. Doctor (2004, this issue) provides a challenging contribution to the enormous and expanding literature on risk, staking a claim for the importance of psychoanalytic psychotherapy in the understanding and management of risk.

\section{What are the claims for a psychodynamic approach to risk?}

Doctor contrasts 'actuarial' and 'clinical' approaches to risk assessment, writing that the actuarial model has failed and that ' $[\mathrm{t}]$ he most reliable risk assessment remains that based essentially on the individual at the clinical level'. He contrasts an essentially mechanical form of actuarial assessment with a clinically based psychodynamic assessment that enters into 'the inner world of patients'. Here he achieves a palpable, if unfair, hit. Unfair because his depiction of 'actuarial' assessment is a caricature. Palpable because, as any reader of the homicide inquiry literature will recognise, time and time again the lack of detailed understanding by services of the perpetrator's mental state, life circumstances and thinking is identified as a key contributory factor to the subsequent tragedy.

Doctor also describes countertransference, which is an important phenomenon that all mental health professionals need to be aware of. Patients, most obviously those with a personality disorder, evoke feelings in staff that may colour therapeutic judgement. He surely goes too far, however, in asserting that '[r]eliable assessment of risk is therefore based primarily on the ability of the worker to perceive and to tolerate unbearable psychic pain'.

Psychodynamic interpretations of events tend to be highly plausible and to be internally consistent within the particular conceptual framework adopted. However, alternative viewpoints may well have greater heuristic value. This is neatly exemplified by the clinical example that Doctor quotes (from Lucas) of a Mental Health Act assessment that did not result in a decision to admit, only for the patient to 
subsequently commit an act of significant violence. A complex psychodynamic account of why the apparent error occurred has some theoretical interest; more practical is a suggestion that the professionals involved be aware of the Mental Health Act Code of Practice and conduct assessments jointly so that all relevant information is readily available at the time of assessment.

Doctor makes confident, if rather confusing, assertions about the role of the psychoanalytically

Box 1 Why risk is not just a burden: some issues raised by questions of risk

The social policy of mental health

- How are policy decisions made?

- How does professional opinion influence decision-making?

- How are decisions implemented?

Epistemology

- On what basis can we predict the future?

- How can we draw valid causal inferences?

Epidemiology

- What are the risks?

- What are the predictors/correlates of risk?

Evidence-based mental health

- What is the evidence for risk statements that are made?

- How do risk assessment tools work in practice?

- Does risk management reduce bad outcomes and if so how?

- What are the effective strategies for reducing bad outcomes in psychiatry?

Risk communication

- How do we inform ourselves and others of risk?

Ethics

- How do we conceptualise personal responsibility for bad actions that are committed?

- What master does the mental health professional serve in making risk decisions?

- Is defensive practice ethical?

Medicolegal

- What comprises negligence?

- How do we avoid criticism when things go wrong?

Clinical practice

- The phenomenology of violent and selfharming behaviour

- Risk management: good practice in care planning

- Patients as parents

- Risk-sharing

- The value of taking risks informed approach in the assessment of violence in the 'paraphilias and borderline states'. The irritatingly knowing tone adopted, typical of psychoanalytic writings for lay people, only serves to underline the poverty of our current understanding of some forms of psychopathology. It is difficult to criticise Doctor's account of psychoanalytic psychotherapy within high security, an environment remote from day-to-day clinical practice that presents unique challenges. An assertion of the psychotogenic effects of becoming consciously aware of previously denied violent behaviour, i.e. that the truth can send you mad, surely goes far beyond the minimal available evidence (it certainly wasn't reflected by my Medline search on the topic).

\section{Conclusions}

Doctor provides a valuable complement to the more empirical literature on risk assessment and risk management. He and his colleagues are to be saluted for their willingness to work with patient groups that are highly marginalised in our society and for offering some conceptual framework for understanding the extremes of human behaviour. His contribution needs to be read in a different way to what is traditionally understood as evidence-based medicine. It raises important questions about how we make sense of difficult things (such as 'evil') and suggests that as humans we need explanatory models to provide a rationale for our actions. However, Doctor and his colleagues need to establish their assertions on a firmer factual basis. We all need to learn how to combine clinical wisdom with reliable evidence.

\section{References}

Appleby, J., Shaw, J., Sherratt, J., et al (2001) Safety First: Five Year Report of the National Confidential Inquiry into Homicides and Suicides by People with a Mental Illness. London: Department of Health.

Doctor, R. (2004) Psychodynamic methods in risk assessment and management. Advances in Psychiatric Treatment, 10, 267-272.

Holloway, F. (1996) Community psychiatric care: from libertarianism to coercion. "Moral Panic" and mental health policy in Britain. Health Care Analysis, 4, 235-243.

House of Commons Health Committee (2003) The Victoria Climbie Inquiry Report. Sixth Report of Session 2002-2003. Report and Formal Minutes together with Oral Evidence. London: Stationery Office. http://www.parliament.the-stationeryoffice.co.uk/pa/cm200203/cmselect/cmhealth/570/ 570.pdf

Frank Holloway is a consultant psychiatrist and Clinica Director of Croydon Integrated Adult Mental Health Services (Bethlem Royal Hospital, Monks Orchard Road, Beckenham, Kent BR3 3BX, UK. E-mail: f.holloway@iop.kcl.ac.uk). His research interests include mental health services research and the social policy of mental health. As clinical governance lead in Croydon, he has responsibility for implementing local and national policies on the assessment and management of risk. 